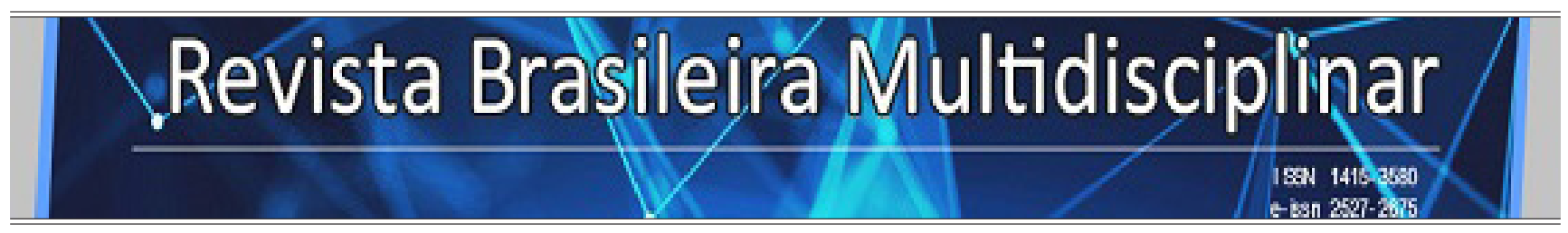

http://revistarebram.com/index.php/revistauniara

\title{
TESTE DE TOXIDADE DO LODO DE CURTUME NA GERMINAÇÃo DE ALFACE
}

Gislayne de Araujo Bitencourt*; Loui Arthur Duarte**; Valdemir Antônio Laura ${ }^{\star * *}$.

* Doutora em Ciências, atua na área de ecologia aplicada Universidade Estadual de Mato Grosso do Sul - UEMS.

${ }^{* *}$ Discente do curso de Engenharia Florestal Universidade Estadual de Mato Grosso do Sul - UEMS .

***Pesquisador Empresa Brasileira de Pesquisa Agropecuária, Centro Nacional de Pesquisa de Gado de Corte, Campo Grande, MS.

*Autor para correspondência e-mail: gislaynebitencourt@gmail.com

\section{Palavras-chave}

\section{Cromo}

Fitotoxidade

Lodo

Resíduo

Tratamento do couro

\section{KEYWORDS}

Chrome

Phytotoxicity

Sludge

Residue

Leather Treatment
Resumo: O processo de produção de couro do tipo wet-blue produz elevada quantidade de resíduos, sendo conhecido como lodo de curtume, que apresenta o cromo na sua constituição, considerado nocivo ao meio ambiente. Objetivou-se avaliar a toxicidade de lodo de curtume na germinação de Lactuca sativa L. (alface). Sementes de alface (cv. babá de verão) foram distribuídas em caixa gerbox contendo papel filtro umedecido com a solução de lodo nas concentrações de $0 ; 12,5 ; 25 ; 50 ; 75$ e $100 \%$, mantidas em câmara de germinação a $25^{\circ} \mathrm{C}$, com fotoperíodo de 12 horas por cinco dias. Utilizou-se o delineamento inteiramente casualizado com três repetições. O lodo de curtume a partir de $25 \%$ promoveu reduções em todas as variáveis avaliadas. A concentração de $100 \%$ inibiu a germinação apresentando efeitos letais de toxicidade.

\section{TANNERY SLUDGE TOXICITY TEST IN LETTUCE GERMINATION}

The wet-blue leather production process produces a high amount of waste, being known as tannery sludge, which contains chrome in its constitution, considered harmful to the environment. The objective was to evaluate the toxicity of tannery sludge at different concentrations in the germination and initial growth of Lactuca sativa L. (lettuce). Lettuce seeds (cv. Summer nanny) were distributed in a gerbox box containing filter paper moistened with the sludge solution in concentrations of $0 ; 12.5 ; 25 ; 50 ; 75$ and $100 \%$, maintained in germination chamber at $25^{\circ} \mathrm{C}$ and 12 hours photoperiod for five days. A completely randomized design with three replications was used. Tannery sludge from $25 \%$ promoted reductions in all evaluated variables. The concentration of $100 \%$ inhibited germination, showing toxicity effects. 


\section{INTRODUÇÃo}

O processo de curtimento do couro bovino envolve etapas de tratamento mecânico e químico, o que gera elevada quantidade de resíduos. Esses resíduos são constituídos por alta concentração de matéria orgânica e elementos químicos, que podem apresentar toxicidade e ocasionar a contaminação do meio ambiente (LEMKE-DE-CASTRO et al., 2015; SANTOS et al., 2014).

O final do tratamento produz a água residuária que é constituída por material sólido e dissolvido, que é mantido em lagoas de decantação, o material que sedimenta no fundo das lagoas é conhecido como lodo de curtume, que após processo de secagem é retirado e armazenado para posterior descarte (ALMEIDA et al., 2017).

A destinação do lodo de curtume é realizada nos aterros sanitários, apresentando um elevado risco de contaminação pelo acúmulo de elementos potencialmente tóxicos, aumentando a probabilidade de contaminação de solo e água (GONÇALVES et al., 2014a; 2014b).

A magnitude econômica atrelada a indústria curtumeira associada ao seu potencial poluidor, vêm motivando a realização de pesquisas para aumentar o conhecimento sobre alternativas econômicas e tecnicamente viáveis, além de ambientalmente vantajosas para a utilização desse resíduo (BERILLI et al., 2014).

Diante disso, é necessário o conhecimento das características físicas, químicas, biológicas e toxicológicas dos resíduos, para que os mesmos possam ser utilizados com segurança e não causem impactos negativos no meio ambiente e nos vegetais. De acordo com Fuentes et al. (2004) para a aplicação de um resíduo no solo é necessária a avaliação de sua toxicidade e, neste contexto, os organismos-teste mais utilizados são plantas.

Os testes ecotoxicológicos padronizados pela Associação Brasileira de Normas Técnicas (ABNT), é uma complementação a análise química, que busca conhecer a consequência da liberação de substâncias químicas diretamente sobre a germinação e crescimento inicial, monitoramento os efeitos letais, morfológicos e fisiológicos (ISO 11269-2, 2014).

A alface (Lactuca sativa L.) é a espécie padronizada para a realização de bioensaios de toxicidade, considerada bioindicadora, utilizada na avaliação de fitotoxicidade devido germinação rápida e uniforme, além de expressar resultados em baixas concentrações de substâncias tóxicas (BARSZCZ et al., 2019; RAMIRES et al., 2019; AZAMBUJA et al., 2010). Partindo desse pressuposto, o objetivo com este estudo foi avaliar a toxicidade de lodo de curtume na germinação da espécie bioindicadora Lactuca sativa L. (alface).

\section{Material e Métodos}

As amostras do lodo de curtume foram cedidas pela Embrapa Gado de Corte, localizada em Campo Grande - MS. O experimento foi conduzido no laboratório de fitossanidade (FITOSSAN) da Universidade Estadual de Mato Grosso do Sul, Unidade Universitária de Aquidauana, MS, coordenadas 5567’ Oeste e $20^{\circ} 45^{\prime} \mathrm{Sul}$, de clima tropical sub-úmido (Aw) com verão chuvoso e inverno seco, temperatura média anual de $26^{\circ} \mathrm{C}$, região ecótono Cerrado - Pantanal.

Uma amostra de lodo foi encaminhada para análise química no Ribersolo Laboratório de Análise Agrícola, na qual foi quantificado cálcio (Ca), cromo (Cr), Na (sódio) e magnésio (Mg), conforme metodologia descrita em Tedesco et. al. (1995) (Tabela 1).

O lodo de curtume foi seco e diluído em água destilada numa proporção de 1:4, em seguida agitado durante duas horas em mesa agitadora, com posterior repouso a $4^{\circ} \mathrm{C}$ por 24 horas. Posteriormente, foram centrifugadas em centrífuga por 5 min sendo coletado o sobrenadante da solução. A solução foi novamente diluída com água destilada em seis concentrações de $0 ; 12,5 ; 25 ; 50 ; 75 ;$ e $100 \%$.

As sementes de alface (cv. babá de verão) foram distribuídas em caixa gerbox contendo papel filtro como substrato, umedecido com $7 \mathrm{~mL}$ do lodo de curtume nas seis concentrações e foi realizado um controle negativo com $\mathrm{NaCl} 1,0 \mathrm{~N}$. O NaCl é utilizado para validar o ensaio, pois sua alta concentração promove a inibição da germinação da semente. 
As sementes foram distribuídas em duas fileiras de 10, totalizando 20 sementes em cada gerbox, com três repetições para cada tratamento, mantidos em câmara de germinação tipo BOD com temperatura controlada $25 \pm 2^{\circ} \mathrm{C}$ e fotoperíodo de 12 horas, por um período de cinco dias, de acordo com recomendações de Brasil (2009).

O delineamento experimental utilizado foi inteiramente casualizado com três repetições. Ao final dos experimentos, foram determinadas as porcentagens de germinação (PG), comprimento de raiz (CR) e de parte aérea das plântulas $(\mathrm{CP})$.

Os dados obtidos foram submetidos a análise de variância (teste F) e as médias foram ajustadas aos modelos de regressão utilizando o programa estatístico SISVAR (FEREIRA, 2019).

Tabela 1 - Caracterização física e química do lodo de curtume.

\begin{tabular}{cccccccc}
\hline $\mathbf{p H}$ & $\mathbf{C e}$ & $\mathbf{N}$ & $\mathbf{P}$ & $\mathbf{C a}$ & $\mathbf{C r}$ & $\mathbf{N a}$ & $\mathbf{M g}$ \\
$\mathrm{CaCl}_{2}$ & $\mu \mathrm{S} / \mathrm{cm}^{-1}$ & $\mathrm{~g} . \mathrm{kg}^{-1}$ & $\mathrm{mg} \cdot \mathrm{dm}^{-3}$ & $\mathrm{cmolc} \cdot \mathrm{dm}^{-3}$ & $\mathrm{mg} \cdot \mathrm{kg}^{-1}$ & $\mathrm{mg} \cdot \mathrm{dm}^{-3}$ & $\mathrm{cmolc.dm}^{-3}$ \\
\hline 7,85 & 2890 & 13,58 & $\mathrm{TF}$ & 21,3 & 8400 & 4,8 & 6,1 \\
\hline
\end{tabular}

$\mathrm{pH}=$ potencial hidrogênio iônico; $\mathrm{Ce}=$ condutividade elétrica; $\mathrm{N}=$ nitrogênio amoniacal; $\mathrm{P}=$ fósforo disponível; $\mathrm{Ca}=$ cálcio; $\mathrm{Cr}=$ cromo; $\mathrm{Na}=$ sódio; $\mathrm{Mg}=$ magnésio; $\mathrm{TF}=$ traços de fósforo.

Fonte: Elaborado pelos autores.

\section{Resultados e Discussão}

Com base nos resultados da análise de variância, verificou-se efeito significativo das concentrações de lodo de curtume na porcentagem de germinação $(\mathrm{PG})$, comprimento de raiz $(\mathrm{CR})$ e de plântula $(\mathrm{CP})$ ao nível de $5 \%$ de probabilidade (Tabela 2 ).

Tabela 2 - Resumo da análise de variância (teste F) para porcentagem de germinação (PG), crescimento, em centímetros, da raiz (CR) e da parte aérea (CPA) de alface submetida a diferentes concentrações $(0,12,5 ; 25 ; 50 ; 75$ e $100 \%)$ de lodo de curtume.

\begin{tabular}{lcccc}
\hline Fontes de variação & GL & PG & CR & CP \\
\hline Concentração & 5 & $78,28^{\star}$ & $45,84^{\star}$ & $33,03^{\star}$ \\
Erro & 12 & & & \\
\hline CV\% & & 10,37 & 23,51 & 22,19 \\
\hline
\end{tabular}

*significativo $(\mathrm{p}<0,05) \mathrm{GL}=$ Grau de Liberdade; $\mathrm{CV}=$ coeficiente de variação.

Fonte: Elaborado pelos autores.

A redução na porcentagem de germinação se enquadrou em um modelo de regressão quadrática, ou seja, reduziu a germinação partir da concentração de $25 \%$ em função do aumento das concentrações de lodo de curtume (Figura 1).

A concentração de $100 \%$ promoveu inibição da germinação nas sementes de alface, sugerindo que 
ocorreu efeito tóxico letal do lodo de curtume.

A condutividade elétrica é um parâmetro que precisa ser verificado, pois altas quantidades de sais prejudicam a germinação. A análise química do lodo de curtume evidenciou uma elevada condutividade, sugerindo que esse parâmetro associado ao $\mathrm{pH}$ acima de 7,85 podem promover condições de estresse salino (Tabela 1).

Figura 1 - Porcentagem de germinação (\%) de alface submetidas a diferentes concentrações de lodo de curtume.

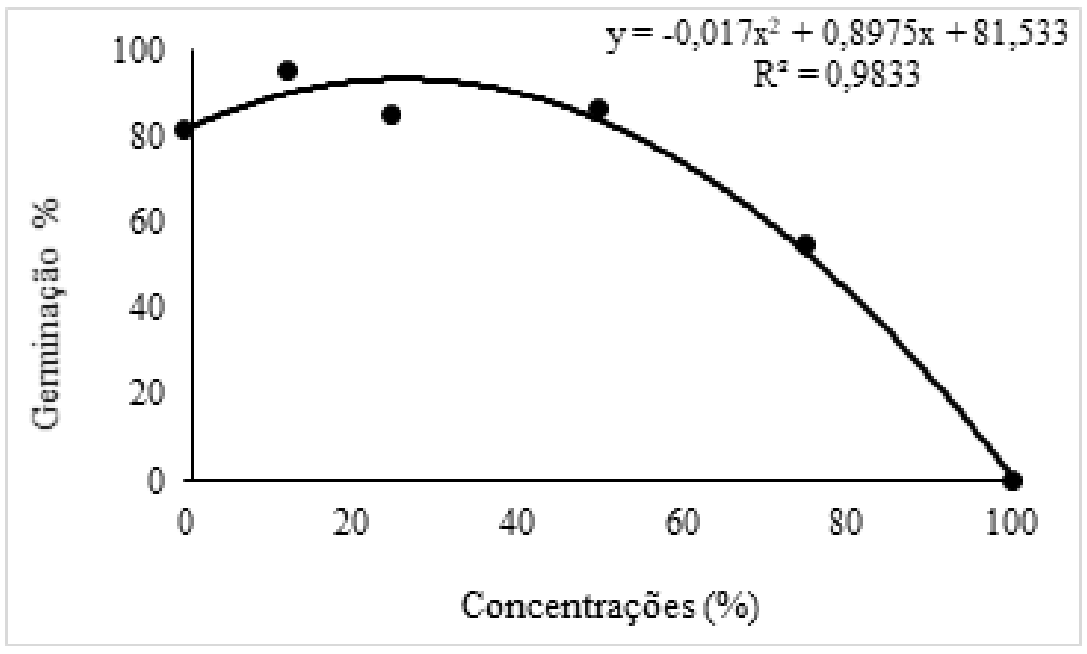

Fonte: Elaborado pelos autores.

O excesso de sais no substrato provoca nas estruturas subcelulares a redução no potencial hídrico provocando uma redução do potencial hídrico, reduzindo a capacidade de absorção de água pelas sementes, afetando a velocidade e o tempo de germinação, além de interferir no desenvolvimento das plântulas, quando as sementes são expostas a níveis não tóxicos (RABBANI et al., 2013; LOPES; MACEDO, 2008). Fato esse, pode estar relacionado com as elevadas concentrações de $\mathrm{Ca}$ e $\mathrm{Na}$ analisadas no lodo de curtume (dados apresentados na tabela 1).

Ademais, sugere-se uma maior sensibilidade atribuída ao fato de germinar as sementes diretamente em contato com a substância. Com base nos trabalhos de (QUADRO et al., 2019; BERILLI et al., 2018; 2014; ARAUJO, 2011) essa sensibilidade não foi observada quando utilizou o lodo de curtume em mudas, estacas ou na fertirrigação foliar.

Alguns autores mencionam a inibição da germinação e crescimento das raízes de alface em bioensaios semelhantes. Franco et al. (2017) verificou a germinação das sementes utilizando lixiviado de aterro sanitário bruto e observou a inibição na germinação. Thode Filho et al. (2019) analisou a germinação das sementes e o comprimento das raízes em extrato contendo bagaço de cana de açúcar residual.

Coser et al. (2010), avaliou a salinidade na germinação de alface e reiteram que os bioensaios, são práticos e de baixo custo, de rápida execução e de alta sensibilidade a presença de substâncias tóxicas ou inibidoras. De acordo com o mesmo autor, foi verificada a inibição da germinação de alface cv. Maravilha Quatro estações em substância salina.

Conforme Vasconcellos et al. (2012), a germinação de alface em placas de Petri é a melhor metodologia para detectar sensibilidade aos agentes tóxicos. Além do mais, Silva e Villas Boas (2007), relatam que valores inferiores a 55\% de germinação já são considerados indicativos de toxicidade.

Observou para a variável comprimento de raiz, o decréscimo função do aumento das concentrações 


\section{Bitencourt et al.}

de lodo de curtume, enquadrando em um modelo de regressão quadrática (Figura 2).

Resultados similares foram citados por Nascentes et al. (2019) em um experimento semelhante utilizando sementes de Zea Mays e observaram redução no comprimento de raiz e de parte área quando utilizada a concentração de $100 \%$ do lixiviado de aterro sanitário.

Figura 2 - Comprimento de raiz (CR) de alface submetidas a diferentes concentrações de lodo de curtume.

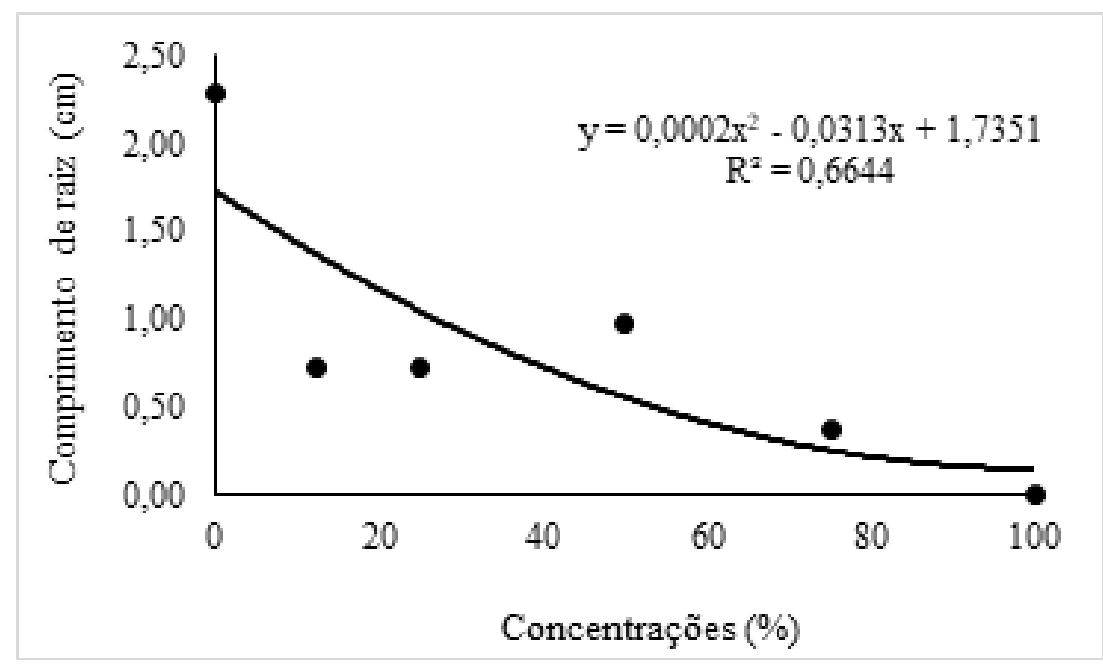

Fonte: Elaborado pelos autores.

O comprimento de plântula reduziu de maneira linear decrescente com o aumento da concentração de lodo de curtume (Figura 3).

Figura 3 - Comprimento de plântula (CP) de alface submetidas a diferentes concentrações de lodo de curtume.

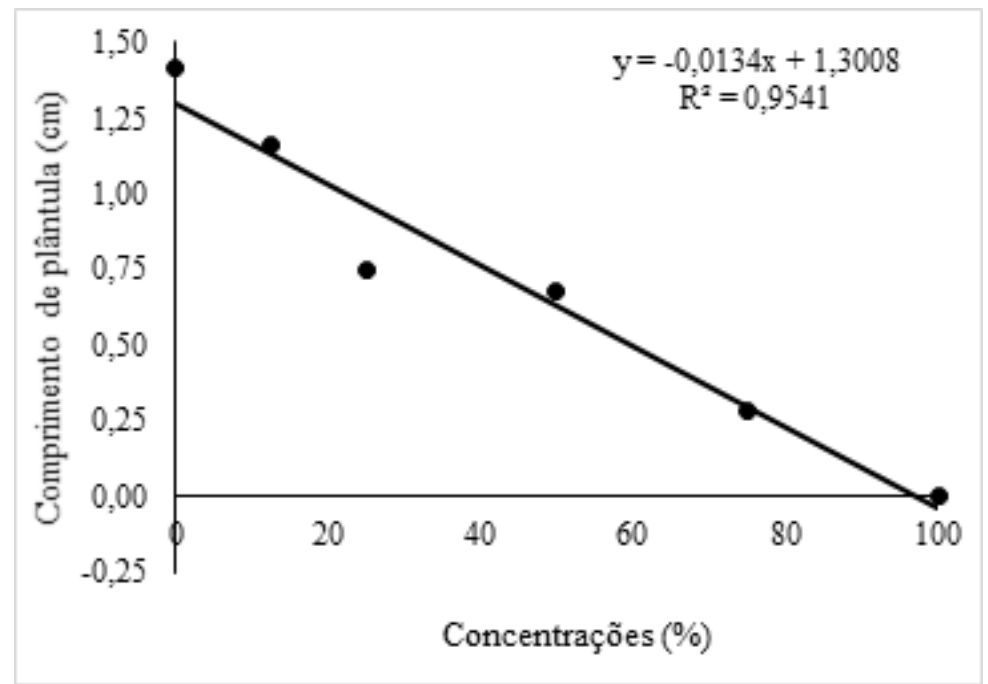

Fonte: Elaborado pelos autores.

Segundo Gryczak et al. (2018), a toxicidade depende da concentração e das propriedades das substâncias químicas que o organismo é exposto e do tempo de exposição. Nesse caso, concentrações acima de 
25\% de lodo de curtume promoveram redução na germinação e desenvolvimento das plântulas de alface.

A análise da composição química do lodo de curtume, evidenciou o excesso de cromo $(\mathrm{C})$, sódio $(\mathrm{Na})$ e cálcio (Ca) na amostra (Tabela 1), fato esse associado a elevada condutividade, que provocou a redução em todas as variáveis avaliadas nas plântulas de alface.

De acordo com Silva et al. (2011) a presença de cromo e do sódio em excesso no lodo de curtume são provenientes do processo de beneficiamento do couro, fatores considerados limitantes para seu uso agrícola. Diferentemente foi citado por Araujo (2011), que concluiu que o cromo contido no lodo de curtume em altas doses não foi o responsável pelos efeitos fitotóxicos, pois o $\mathrm{pH}$ acima de 5,0 promove a precipitação do cromo em forma insolúvel.

Com base na literatura, elevadas concentrações de sódio no lodo de curtume provocam o aumento da condutividade elétrica, características essas atribuídas a solos salinos, que foram verificadas quando as sementes foram submetidas em solução contendo lodo de curtume nesse bioensaio (RABBANI et al., 2013).

Deficiências nutricionais podem ser oriundos do excesso de cálcio presente nas altas concentrações do lodo de curtume, que possivelmente reduziu a absorção de $\mathrm{Mg}$, induzindo a deficiências nutricionais (BATISTA; ALOVISI, 2010).

O teste de toxicidade é um ensaio preliminar que pode dar respostas de como os ecossistemas metabolizam, transformam, degradam, acumulam, eliminam ou sofrem a ação das diversas substâncias químicas neles introduzidas (BALAN et al. 2017). Estes resultados são ainda primários e sugerimos mais testes, com aplicação em solo com um maior período de avaliação.

\section{CONCLUSÃo}

O teste de toxicidade utilizando sementes de alface revelou ser uma excelente ferramenta para verificação dos efeitos tóxicos do lodo de curtume, sendo de baixo custo, rápida execução e alta sensibilidade.

O experimento evidenciou que o lodo de curtume na concentração acima de $25 \%$ promoveu reduções em todas as variáveis avaliadas. A concentração de $100 \%$ de lodo de curtume inibiu a germinação e crescimento inicial de alface, apresentando efeitos letais de toxicidade.

\section{REFERÊNCIAS}

ALMEIDA, R.N.; FERRAZ, D.R.; SILVA, A.S.; CUNHA, E.G.; VIEIRA, J.C.; SOUZA, T. da. S.; BERILLI, S.da.S. Utilização de lodo de curtume em complementação ao substrato comercial na produção de mudas de pimenta biquinho. Revista Scientia Agraria, Curitiba, v. 18, n. 1, p. 20-33, 2017. DOI: http://dx.doi. org/10.5380/rsa.v18i1.49914.

ARAUJO, F.F.de. Disponibilização de fósforo, correção do solo, teores foliares e rendimento de milho após a incorporação de fosfatos e lodo de curtume natural e compostado, Acta Scientiarum Agronomy, v.33, n.2, p. 355-360, 2011.

AZAMBUJA, N.; HOFFMANN, C.E.F.; DAS NEVES, L.A.S.; GOULART, E.P.L. Potencial alelopático de Plectranthus barbatus Andrews na germinação de sementes de Lactuca sativa L. e de Bidens pilosa L. Revista Ciências Agroveterinárias, n. 9 v.1, p.66-73, 2010.

BATISTA, M.M.; ALOVISI, A.M.T. Alterações de atributos químicos do solo e rendimento da cana soca pela utilização de lodo de curtume. Anuário da Produção de Iniciação Científica, v. 13, n. 17, p. 387-396, 2010.

BALAN, D. de. S. L. Corantes naturais de aplicação têxtil: avaliação preliminar da toxicidade de urucum 
Bixa orellana L. (Malvales: Bixaceae) e hibisco Hibiscus sabdariffa L. (Malvales: Malvaceae). Revista Brasileira de Gestão Ambiental e Sustentabilidade, v.4, n.7, p.151-157, 2017. http://dx.doi.org/10.21438/ $\underline{\text { rbgas.040715 }}$

BARSZCZ, L.B.; BELLATO, F.C.; BENASSI, R.F.; MATHEUS, D.R. Avaliação ecotoxicológica de efluentes tratados por alagados construídos. Engenharia Sanitária e Ambiental, v. 24, n.6, p. 1147-1156, 2019. https://dx.doi.org/10.1590/s1413-41522019184120

BERILLI, S.S.DA.; QUIUQUI, J.P.C.; REMBINSKI, J.; SALLA, P.H.H.; BERILLI, A.P.C.G.; LOUZADA, J.M. Utilização de lodo de curtume como substrato alternativo para produção de mudas de café conilon. Coffee Science, v. 9, n. 4, p. 472 - 479, 2014.

BERILLI, S.S.; PEREIRA, L.C.; PINHEIRO, A.P.B.; CAZAROTI, E.P.F.; SALES, R.A.de.; LIMA, C.F. Adubação foliar com lodo de curtume líquido no desenvolvimento e qualidade de mudas de maracujá-amarelo. Revista Brasileira de Agricultura Irrigada, v.12, n.2, p. 2477 - 2486, 2018. DOI: 10.7127/rbai.v12n200762

BRASIL, Ministério da Agricultura e Reforma Agrária. Regras para Análise de Sementes. BRASÍLIA: 2009. 395. https://www.abrates.org.br/files/regras analise de sementes.pdf

FERREIRA, D.F. SISVAR: a computer analysis system to fixed effects split plot type designs. Revista brasileira de biometria, v. 37, n. 4, p. 529-535, 2019.

FRANCO, H.Á.; MARTINS, G.M. de O.; MUSSEL, Y.L.; MORENO, S.C.; THODE FILHO, S.; MARQUES, M.R. da C. Ecotoxicidade de Lixiviado de Aterro Sanitário na Germinação de Sementes de Alface (Lactuca sativa L.) e Pepino (Cucumis sativus L.). Revista de Estudos Ambientais, v. 19, n. 1, p. 36-43, 2017. DOI: http://dx.doi.org/10.7867/1983-1501.2017v19n1p36-43

FUENTES, A.; LLORENS, M.; SAEZ, J.; AGUILAR, M.I.; ORTUÑO, J.F.; MESEGUER, V.F. Phytotoxicity and heavy metals speciation of stabilized sewage sludges. Journal of Hazardous Materials, v. 108, p. 161-169, 2004.

GONÇALVES, L.C.R.; ARAÚJO, A.S.F.; NUNES, A.P.L.; BEZERRA, A.A.C.; MELO, W.J.de. Soil microbial biomass after two years of the consecutive application of composted tannery sludge. Scientiarum Agronomy, n. 1, p. 35-41, 2014a.

GONÇALVES, L.C.R.; ARAÚJO, A.S.F.; NUNES, A.P.L.; BEZERRA, A.A.C.; MELO, W.J.de.. Heavy metals and yield of cowpea cultivated under composted tannery sludge amendment. Acta Scientiarum Agronomy, v. 36, n. 4, p. 443-448, 2014 b.

GRYCZAK, M.; KILIPPER, T. J.; COSTA, D. P.; MACCARI, A. Sementes de Lactuca sativa como bioindicador de toxicidade em resíduos de construção civil. Revista Tecnologia e Ambiente, v. 24, p. 233-242, 2018.

INTERNATIONAL ORGANIZATION FOR STANDARDIZATION. ISO 1269:2. Qualidade do solo determinação dos efeitos de poluentes na flora terrestre. 2. ed. Rio de Janeiro, 2014. 23 p.

LEMKE-DE-CASTRO, M.L.; BORGES J.D.; LEANDRO W.M. Sorção competitiva entre cádmio e cro- 
mo em latossolo variando pH e eletrólito de suporte. Revista Brasileira de Ciências Agrárias, v.10, n.3, p.396-402, 2015.

LOPES, J.C.; MACEDO, C.M.P. Germinação de sementes de sob influência do teor de substrato e estresse salino. Revista Brasileira de Sementes, v.30, p.79-85, 2008.

NASCENTES, A.L.; PEREIRA, B.C.; PINHO, C.F. de.; SILVA, L.D.B. da.; ZONTA, E.; FERREIRA, J.A.; CAMPOS, J.C. Avaliação da toxicidade de lixiviado de aterro sanitário utilizando germinação de sementes de milho. Revista de estudos ambientais, v.21, n. 2, p.20-30, 2019. DOI: http://dx.doi.org/10.7867/ $\underline{1983-1501.2019 v 21 n 2 p 20-30}$

QUADRO, M.S.; F.A.de. O.; GIANELLO, C.; DALLAGNOL, A.L.B.; Demarco, C.F.; Andreazza, R. Crescimento e teor de cromo em mamoneira cultivada em solo receptor de resíduos de curtume e carboníferos. Engenharia Sanitária Ambiental, v.24 n.6, p. 1095-1102, 2019.

RABBANI, A.R.C.; SILVA-MANN, R.; FERREIRA, R.A.; CARVALHO, S.V.Á.; NUNES, F.B.S.; BRITO, A.S. Efeito do estresse salino sobre atributos da germinação de sementes de girassol. Scientia plena, v.9, n.5, p.1-6, 2013.

RAMIRES, M.F.; SOUZA, E.L. de; FONTANIVE, D.E.; BIANCHETTO, R.; KRYNSKI, A.M.; CEZIMBRA, J.C.G.; ANTONIOLLI, Z.I. Ecotoxicology of Pig Slaughterhouse Waste Using Lactuca sativa L., Raphanus sativus L., and Oryza sativa L.. Revista Brasileira de Ciência do Solo, v. 43, e0180119, 2019. https://doi. org/10.1590/18069657rbcs20180119

SANTOS, J.L.; ARAÚJO A.S.F.; NUNES, L.A.P.L.; OLIVEIRA M.L.J.; MELO, W.J. Chromium, Cadmium, Nickel, and Lead in a Tropical Soil after 3 Years of Consecutive Applications of Composted Tannery Sludge. Communications in Soil Science and Plant Analysis, v. 45, n. 12, p. 1658-1666, 2014.

SILVA, F. A. de M.; VILLAS BÔAS, R. L. Teste de germinação como indicador de maturação em composto orgânico. Revista Energia na Agricultura, v. 22, n. 2, p. 63-73, 2007.

SILVA, C. da. D. J.; LEAL, B. T. T.; ARAÚJO, M. R.; GOMES, F. L. R. ARAÚJO, de F.S. A.; MELO, de J. W. Emergência e crescimento inicial de plântulas de pimenta ornamental e celosia em substrato a base de composto de lodo de curtume. Ciência Rural, Santa Maria, v.41, n.3, p.412-417, 2011.

TEDESCO, M.J.; GIANELLO, C.; BISSANI, C.A.; BOHNEN, H.; VOLKWEISS, S. J. Análise de solo, plantas e outros materiais. 2.ed. Porto Alegre: UFRGS-Departamento de Solos, 1995. 174p. (Boletim Técnico).

THODE FILHO, S.; PAIXÃO, C.P.S. da.; MARANHÃO, F.da. S.; FRANCO, H.A. Avaliação ecotoxicológica do extrato solubilizado de bagaço de cana-de-açúcar residual via germinação de sementes de alface (Lactuca sativa L.). Revista de estudos ambientais, v.21, n. 1, p.46-55, 2019. DOI: http://dx.doi. org/10.7867/1983-1501.2019v21n1p46-55

VASCONCELlOS, M. C.; PIMENTEL, M. A.; PENHA, R. O.; GUERRA, E. P.; SILVA, L. L. Ação de diferentes enzimas na germinação de sementes de alface (Lactuca sativa L) -Asteraceae. Journal of Biotechnology and Biodiversity, v. 3, n. 3, p. 1-4, 2012. 